\title{
AS PAIXÕES TRANSMUTADAS EM VIRTUDES. ACERCA DE UM DILEMA NO PENSAMENTO ÉTICO DE NIETZSCHE
}

\author{
Clademir Luís Araldi \\ Universidade Federal de Pelotas
}

\begin{abstract}
We can find in the nietzschian thought the two basic processes of transmutation of passions into virtues: 1) in the ethics of nobility, the sublimation of passions into virtues engenders affirmative values and 2) in the slave morality, the passions are degraded into virtues, losing their original natural vigor. We will investigate in this article is if the two described processes have as result the depotentiation of passions and in what senses this depotentiation occurs.
\end{abstract}

Keywords: passions, virtues, transmutation, sublimation, ethics.

Resumo: Podemos encontrar no pensamento nietzschiano dois processos básicos de transmutação das paixões em virtudes: 1) na ética da nobreza, a sublimação das paixões em virtudes engendra valores afirmativos e 2) na moral dos escravos, as paixões são degradadas em virtudes, perdendo seu vigor natural original. Investigaremos nesse artigo se os dois processos descritos têm como resultado a despotenciação das paixões e em que sentidos essa despotenciação ocorre.

Palavras-chave: paixões, virtudes, transmutação, sublimação, ética.

A relação entre as paixões (impulsos, afetos) e as virtudes é uma questão relevante no pensamento ético moderno e contemporâneo. Hume procurou aplicar, no Tratado da natureza humana, o empirismo nos "assuntos morais", de modo a assegurar uma boa configuração dos impulsos no campo da ética. O jovem filósofo escocês presumia que os mesmos "princípios naturais e necessários", que garantem a coesão dos poderes e elementos da natureza em geral, atuariam também na natureza humana. 
Com base nisso, seria possível provar empiricamente que as ações dos homens têm uma união constante com os motivos, com o caráter e com as circunstâncias neles envolvidos (Hume, 2009, p. 437). Apesar da irregularidade e da inconstância aparentes da conduta humana, poder-se-ia explicar a necessidade das ações humanas, sem recorrer à Razão. $\mathrm{O}$ embate inquietante entre paixões fortes e fracas, calmas e violentas está desvinculado da razão teórica ou prática. Hume critica severamente as pretensões da filosofia racionalista e metafísica, de regular as ações pela Razão. Por si só, a razão jamais pode ser motivo para uma ação da vontade humana. A doutrina da necessidade das ações permite explicar o modo como os objetos nos afetam, a partir das impressões que resultam imediatamente do prazer e da dor. Na complexa relação entre impressões e ideias, é a paixão que se coloca como princípio da ação. A virtude mesma é uma percepção da mente; não é nenhuma qualidade do e no objeto, mas objeto de uma sensação ou sentimento (a feeling or sentiment) (Hume, 2009 , p. 508 ss.), ou seja, de uma impressão, por mais branda que pareça. O prazer é sempre o traço distintivo da virtude.

Schopenhauer, seguindo de certo modo as trilhas do filósofo escocês, propõe uma investigação empírica para repensar a dinâmica dos impulsos humanos. A motivação moral tem de ser real e empírica, visto que a moral "tem a ver com a ação efetiva do ser humano". Nesse sentido, o autor de Sobre o fundamento da moral, busca determinar a lei da motivação, a saber, o impulso próprio que move ações que possuem valor moral:

Por isto, resta apenas para a descoberta do fundamento da ética o caminho empírico, a saber, o de investigar se há em geral ações às quais temos de atribuir autêntico valor moral - que seriam as ações de justiça espontânea, pura caridade e generosidade efetiva (Schopenhauer, 2001, p. 119).

Somente as ações altruístas, destituídas de qualquer motivação egoísta, teriam autêntico valor moral. Chegamos, no entanto, no ponto em que Schopenhauer se detém no seu procedimento analítico, que vai das consequências às causas das ações com valor moral. Não basta afirmar que

1 SCHOPENHAUER, 2001, p. 51-52. 
a compaixão é a verdadeira motivação moral, a única fonte ou fundamento da moralidade, ou seja, das virtudes "cardeais" da justiça e da caridade (cf. Schopenhauer, 2001, p. 175 s.). A compaixão, apesar disso, continua sendo “o maior mistério da ética”. É necessário para ele explicar, expor e, mais do que isso, fundamentar metafisicamente o fenômeno ético originário da compaixão. Uma investigação psicológica, empírica ou genealógica não daria conta dessa dificílima tarefa. Aliás, o problema não pode ser resolvido no terreno próprio da ética, pois a simples constatação da efetividade das ações caritativas, provindas da compaixão, não é suficiente. Entretanto, essas ações são "misteriosas" no seu fundamento último. O filósofo pessimista paradoxalmente procura fundamentar a moral a partir de uma intuição (não empírica, não intelectual), que permitiria captar imediatamente o caráter próprio, imutável de si mesmo como coisa em si.

Esse horizonte metafísico, delineado já na primeira edição de $O$ mundo como vontade e representação, encerra dificuldades consideráveis para a investigação do caráter moral das ações. Uma ação boa (justa, caritativa) resultaria de um caráter bom (imutável, inato), preponderantemente susceptível a motivos caritativos ${ }^{2}$. Novamente, o problema é projetado para um horizonte metafísico inexplicável. No âmbito das ações, do operari, não há propriamente liberdade e responsabilidade. $\mathrm{O}$ agir procede do ser, ou seja, da coisa em si, da vontade de viver que é uma, indivisa no caráter próprio de cada ser humano. Podemos com certa facilidade antever a suspeita nietzschiana nesse procedimento de atribuir liberdade metafísica para a vontade, de afirmar a si mesma em certos atos da vontade (com seus correspondentes impulsos corporais), no egoísmo colossal, essência eterna de cada ser humano. Entretanto, é na mesma essência interna, inata e uma da vontade que se embasaria o fenômeno ético da compaixão. Ao intuir que há em todos os seres vivos, não só no homem, a "mesma essência interna e verdadeira", o caráter bom será espontaneamente motivado a ações justas e caritativas. Os caracteres egoístas e maus, por sua vez, jamais poderiam chegar a essa intuição, por serem motivados pelo egoísmo, enraizado em seu caráter próprio inteligível.

\footnotetext{
${ }^{2}$ Assim Schopenhauer expõe a lei da motivação, segundo a qual o caráter individual se revela em determinadas ações: "... cada qual só será estimulado predominantemente pelos motivos para os quais tem uma sensibilidade preponderante, do mesmo modo que um corpo só reage aos ácidos, outros só aos álcalis; e, da mesma forma que este, também aquele não muda". (Schopenhauer, 2001, p. 196-197)
} 
Essa "metafísica natural", a 'certeza' de cada caráter humano de ser o mesmo em todos, não está e nem pode estar presente em todos os seres humanos, pois a própria vontade, inexplicavelmente, determinou uma imensa diferença entre os caracteres, desde os extremos da crueldade até as mais elevadas e miraculosas manifestações de bondade.

A breve exposição das dificuldades com que Schopenhauer se depara na sua inconclusa fundamentação metafísica da compaixão tem a função de apontar para a necessidade de aprofundar a relação entre os impulsos e o campo ético das virtudes. Em Nietzsche pretendemos investigar os desenvolvimentos do novo método filosófico não metafísico (pautado na História, na fisiopsicologia e na genealogia da moral) para reconstruir a complexa dinâmica de determinados impulsos humanos que se transmutam em virtudes.

O trabalho crítico-desconstrutivo é fundamental para o projeto nietzschiano de estabelecer uma nova ética, a partir de valores naturalistas, a saber, dos impulsos naturais (ou naturalizados) humanos. Como relacionar o mundo natural (dos fatos, fisiológicos, empíricos) com o universo valorativo humano? O foco deste artigo está no aspecto construtivo do pensador solitário alemão: a proposição de novas 'virtudes', sem o caráter moralizante da tradição racionalista e teológica. Para tanto, investigaremos momentos determinantes de obras do período intermediário (sobretudo Humano, demasiado humano e Aurora) e do período de maturidade de Nietzsche (Assim falou Zaratustra, Além do bem e do mal).

Nietzsche não afirma os impulsos humanos em seu caráter espontâneo, imediato, inconsciente e irrefletido da natureza. No pensamento ético que se delineia a partir de Humano, demasiado humano há uma formulação de um lento processo de transmutação (Verwandlung) dos impulsos em virtudes, balizado pela vontade de poder (der Wille zur Macht) de dois modos de vida determinados: do nobre e do escravo. É no nobre que este conceito fundamental e essência de todo o ser e existente - a vontade de poder - poderia transmutar afirmativamente paixões em novas virtudes, a saber, em novos valores e tábuas de bem e mal. Ou seja, a vontade de poder interpreta, valora afirmativamente no nobre; ela é a 'essência' do mundo, e critério para determinação de valores. 


\section{A natureza das paixões e sua transmutação na ética.}

O novo método de investigar as paixões humanas, presente desde Humano, demasiado humano (1878), está fortemente ligado às noções de prazer e desprazer (Lust und Unlust). Nessa investigação de cunho preponderantemente psicológico, todas as ações individuais humanas teriam como meta o prazer e a fuga da dor. Não haveria uma distinção (moral) entre 'boas' e 'más' ações, pois todas elas são motivadas pela busca individual da obtenção e incremento do prazer: “Todas as 'más' ações são motivadas pelo impulso de conservação ou, mais exatamente, pelo propósito individual de buscar o prazer e evitar o desprazer" (MA/HH I, §9).

Essa análise psicológica aparece articulada com considerações históricas, à medida que Nietzsche vincula a formação do sentimento moral com as sensações prazerosas que o indivíduo encontra em si mesmo, e com os novos tipos de prazer advindos da longa história da formação da sociabilidade. Foi sempre a obstinada busca de prazer que moveu os indivíduos a controlar as paixões próprias que poderiam impedir o acesso a novas fontes de prazer, à medida que suas paixões colidem com outras individualidades, com o mesmo objeto de desejo (p. ex., de uma propriedade). O "instinto social" 3 surge como uma nova forma de prazer, adquirida com esforços contínuos e múltiplos. A ampliação do domínio das sensações de prazer decorrente das relações humanas tornou o homem "melhor" em relação ao estado natural pré-civilizatório. A segurança e o bem-estar em desfrutar prazeres comuns diminuíram a hostilidade "natural" entre os humanos, graças à ficção emergente da empatia:

As manifestações de prazer semelhantes despertam a fantasia da empatia (Phantasie der Mitempfindung), o sentimento de ser igual: o mesmo fazem os sofrimentos comuns, as

\footnotetext{
3 Paul Rée, convicto seguidor da teoria da evolução de Darwin, afirma na obra Der Ursprung der moralischen Empfindungen que o instinto social (nas formigas, abelhas) é o desenvolvimento do instinto materno, que por sua vez é fortalecido pela seleção natural. Esse impulso natural para cuidar dos outros torna-se um fenômeno moral no mundo humano. Assim se explicam as sensações prazerosas concomitantes às ações altruístas (RÉE, 2004, p. 131s.). É importante notar que as discussões entre Rée e Nietzsche foram muito importantes na elaboração de Humano, demasiado humano.
} 
mesmas tormentas, os mesmos perigos e inimigos. Com base nisso se constrói depois a mais antiga aliança: cujo sentido é defender-se e eliminar conjuntamente um desprazer ameaçador, em proveito de cada indivíduo. E assim o instinto social nasce do prazer. (MA/HH I, §98)

O que conta nessa perspectiva filosófica é a manutenção e o incremento do poder do indivíduo. Tanto no estado anterior à sociabilidade ${ }^{4}$ quanto na história da moralização (que coincide com a da civilização). Nas presumíveis ações "más", que teriam como meta o sofrimento alheio, e nas ações compassivas, que, ao contrário visam o bem do outro (na diminuição de seu sofrimento), estão em jogo apenas diversos elementos de prazer pessoal, que no fundo expressam o prazer do exercício do poder, da superioridade em relação ao que sofre. Ser causa do sofrimento do outro ou querer aliviar sua dor seriam formas de ações egoístas (cf. MA/HHI, §103).

A coerção do indivíduo coletivo sobre os seres humanos individualizados é vista como necessária para o surgimento da moralidade (cf. MA/HH I, §99). O processo da eticidade (Sittlichkeit) opera uma transformação radical, à medida que a coerção torna-se costume. A força do hábito e dos costumes tornaria prazerosa a prática de ações, que bem mais tarde passam a ser chamadas de "morais". O caráter ético (sittlich) de uma ação, desse modo, é constituído pelo efeito prazeroso dos costumes. Nietzsche, entretanto, diz que o hábito, por ser um gênero de prazer, é fonte da moralidade (Quelle der Moralität). Hábitos praticados de bom grado não são apenas agradáveis, mas também úteis. Assim, após muitas repetições, os hábitos que valem para os indivíduos como sua única condição de existência são adotados por uma comunidade ou povo, constituindo sua eticidade (cf. MA/HH I, §97). É no indivíduo, contudo, que os hábitos (ligados a costumes legitimados socialmente) prazerosos serão sentidos como morais. É o sentimento, potencializado pela apreciação e valoração subjetivas das ações prazerosas, que engendra o caráter moral das mesmas. Nesse ponto já nos deparamos com a interrogação: esse processo denota um

\footnotetext{
${ }^{4}$ Acerca da inscrição da sociabilidade no ser humano, cf. AZEREDO, 2007, p. 76-78. Na passagem da natureza à cultura, a obediência ao costume marcaria, segundo Vânia Azeredo, uma etapa para a formação do humano, que não conduziria a uma mera domesticação, mas ao sentimento do costume, próprio do âmbito da eticidade.
} 
domínio moral objetivo das ações ou é somente um âmbito valorativo, próprio de um indivíduo que estima e interpreta seguindo convenções socialmente aceitas? Por se sentir valioso e vinculado a uma comunidade, o indivíduo decidiria espontaneamente obedecer a valores e leis de uma comunidade moral. O prazer no costume constituiria uma espécie de segunda natureza. Longe de defender um cirenaísmo na ética, o autor de Humano pretende atingir formas elevadas, sutis e espirituais de prazer. $O$ prazer, especialmente o prazer no exercício do poder, é o critério para a valoração das ações. Dele nasceria a virtude.

Essa breve argumentação nietzschiana é insuficiente para descrever o longo processo de formação dos valores e virtudes morais. É necessário reconstruir o processo, apontado por Nietzsche, que circunscreve o prazer no costume (de indivíduos sedentos de poder) no domínio da eticidade do costume. E, por fim, como se dá o passo decisivo - do âmbito extramoral da eticidade do costume para o domínio da moralidade ${ }^{5}$, no qual somente as ações poderiam ser avaliadas ('moralmente') como boas ou más.

$\mathrm{Na}$ conceitualização da eticidade do costume, Nietzsche procura articular uma abordagem histórica pretensiosa (que incide sobre os milênios de constituição dos modos humanos de vida) com considerações psicológicas e filosófico-morais:

Em relação ao modo de vida de milênios inteiros da humanidade, nós, homens de hoje, vivemos numa época muito pouco ética (in einer sehr unsittlichen Zeit): o poder do costume está espantosamente enfraquecido, e o sentimento da eticidade (Sittlichkeit), tão refinado e posto nas alturas, que podemos dizer que se volatilizou. Por isso vêm a ser difícil para nós, que nascemos tardiamente, as percepções fundamentais sobre a gênese da moral $(\mathrm{M} / \mathrm{A}, \S 9)$.

\footnotetext{
${ }_{5}$ Para Volker Gerhardt, a moral afirmada por Nietzsche parte de um indivíduo singular (Einzelne) que busca sua autodeterminação, autodomínio no agir e no pensar. Haveria para Gerhardt, contudo, um núcleo 'racional' nesse indivíduo responsável por si mesmo e senhor de suas virtudes (cf. GERHARDT, 1992, p. 47-49). Somente com o preço demasiado alto de uma 'kantianização' de Nietzsche poderíamos arrancar as ações humanas do movimento afetivo-pulsional (investigado atentamente por Hume), impregnado por uma necessidade irracional.
} 
Com essa percepção fundamental, de que o caráter próprio da humanidade foi fixado nesse longo período da eticidade do costume, ele conclui que até Sócrates e a moral dele advinda, o indivíduo, com pretensão de liberdade, originalidade e autonomia é avaliado como não ético. Se eticidade é "obediência a costumes", toda posição valorativa estritamente individual é condenável. O círculo da eticidade, que compreendia vastos domínios, como educação, saúde, linguagem etc., fecha-se na estrita obediência às leis e aos costumes. Por serem a "maneira tradicional de agir e avaliar" (M/A, §9), os costumes impedem qualquer afirmação de ações, caracteres e modos de ações radicalmente individuais. A autoridade superior da tradição possibilitou a decisiva transmutação dos impulsos da natureza (originária) humana em costumes prazerosos, sentidos e avaliados como éticos, ou seja, vinculados a formas de vida tradicionais.

Os costumes poderiam, assim, atuar sobre a natureza originária dos instintos, transformando-os. Essa é a preocupação do filósofo de Sils-Maria no aforismo de Aurora, que leva o título "Os impulsos transformados pelos juízos morais”. Nele são expostas transmutações decisivas dos impulsos originais do ser humano, até assumirem uma conformação diversa, a saber, uma segunda natureza (eine zweite Natur). Em si e para si mesmos, os impulsos não possuem nenhum caráter ou denominação moral. Através da influência dos costumes (das impressões individuais de louvor e censura que deles decorrem), desenvolvem-se sentimentos agradáveis, como a humildade, ou desagradáveis, como a covardia, que passam por um processo de moralização, sendo por fim ajuizados como bons ou maus. Os juízos de valor moral bom e mau, por sua vez, procedem de modos de viver e de avaliar determinados. Os modos de vida dos nobres, com seus traços típicos de caráter, p. ex., constituem costumes e avaliações tidas como superiores e preponderantes. Nesse movimento, os impulsos em questão adquirem como que uma 'segunda natureza' por meio da "sensação concomitante de prazer ou desprazer". Podemos entender assim, por exemplo, porque a inveja era percebida como boa para os gregos, enquanto para os cristãos ela é condenada por sua pecaminosidade (cf. M/A, §38). Por meio do método genealógico, Nietzsche diagnosticará os dois tipos básicos de transformação dos impulsos pelos juízos morais, a saber, na moral aristocrática (através dos valores bom e ruim [gut - schlecht]) e na moral dos escravos (através dos valores bom e mau [gut - böse]). 
Os sentimentos morais são vistos como expressões de desejos de exercer o poder sobre outros. Fazer bem e mal a outros são formas de exercer o poder neles. $\mathrm{Na}$ obra que fecha o período da filosofia do espírito livre, A gaia ciência, o filósofo solitário propõe uma "teoria do sentimento de poder", em que dor e prazer são instrumentos para aumentar o poder (cf. FW/GC, §13). Não encontramos ali, contudo, a pedra de toque do pensamento ético nietzschiano. Essa psicologia dos impulsos morais não expõe como surgem os valores, a partir das avaliações e formas de vida. Tudo dependeria apenas de como o indivíduo "tempera a sua vida". Ou seja, é uma questão de gosto, do temperamento de indivíduos, tanto dos nobres quanto dos compassivos. Dos sentimentos de dor e prazer não se depreendem naturalmente valores e virtudes tipicamente morais.

Não fica de modo algum claro, a nosso ver, se e como as virtudes e valores típicos dos nobres constituem um domínio próprio da ética, em contraposição à necessidade irrestrita do mundo natural dos impulsos não morais. Apesar de Nietzsche avaliar como superiores as virtudes do nobre, não são expostos os processos de constituição do caráter ético das mesmas. No período pré-moral da eticidade do costume, são os efeitos prazerosos dos costumes que passam a ser chamados de 'virtudes'. Para preparar o domínio da moralidade, é preciso que os indivíduos, espontaneamente, obedeçam às leis e aos costumes da tradição. Mas como esse prazer em seguir costumes da comunidade se torna uma segunda natureza, a saber, virtude?

\section{Uma lacunar genealogia da virtude.}

Nos momentos em que mais se volta para as questões da moral na filosofia do espírito livre, Nietzsche não oferece mais que uma gênese lacunar da virtude. Da coerção do indivíduo coletivo sobre os impulsos dos frágeis indivíduos surgem hábitos, costumes, que fixam o domínio da eticidade. Os sentimentos de prazer e desprazer no exercício do poder da perspectiva de cada indivíduo, membro de uma comunidade, são fontes da moralidade. Não há, contudo, uma investigação histórica ou psicológica que mostre como os juízos morais transformam impulsos brutos dos seres humanos em seu estado de natureza. A partir de que avaliações e formas de vida surgem os valores? Como se configura o caráter dos indivíduos, se é ele quem determina hábitos afirmativos que poderão tornar-se virtudes? 
Afirmar somente "a ânsia de poder intacta" dos impulsos do homo natura ${ }^{6}$ como critério de avaliação aumentaria ainda mais a distância em relação a qualquer projeto ético, com avaliações e valores morais determinados. A partir de Assim falou Zaratustra, Nietzsche se ocupa com mais atenção na investigação de como surgiram as virtudes nos seres humanos. Nessa perspectiva, a história do surgimento das virtudes morais ou extramorais se confunde com a dos valores morais.

$\mathrm{O}$ método genealógico possibilitou a descoberta de dois processos básicos de transformação (Verwandlung, Umwandlung) das paixões em virtudes: 1) Na ética da nobreza, a sublimação das paixões em virtudes tem conseqüências positivas, nos modos e valores afirmativos. As várias aristocracias guerreiras historicamente verificáveis seriam exemplos disso. A sublimação é entendida na época tardia de um novo modo. Na "química" sem espírito dos sentimentos morais, sublimação possuía o sentido bem específico de rarefação do elemento pulsional básico. Já na fisiopsicologia da vontade de poder, a sublimação é entendida como um complexo processo de espiritualização das paixões. 2) A moral dos escravos, em contrapartida, apresenta um processo de consequências nefastas, segundo Nietzsche, à medida que as paixões são degradadas em virtudes. As paixões perdem não apenas seu vigor natural primeiro, nessa forma de moralização, mas todo vínculo com um "naturalismo sadio" na construção de valorações humanas.

Os dois processos descritos, no entanto, ocasionam a despotenciação das paixões. A despotenciação das paixões, no entanto, não ocorre num único sentido ou direção. Para compreender os dois movimentos contrapostos da paixão: a espiritualização e a moralização dos impulsos humanos, abordaremos aspectos determinantes do processo genealógico de transmutação dos afetos $^{7}$ no pensamento intermediário e tardio de Nietzsche, e um dilema com que ele se depara.

$\mathrm{Na}$ época em que começou a investigar com maior concentração a gênese da virtude (em Assim falou Zaratustra) o filósofo solitário desenvolve também o conceito central da vontade de poder no âmbito valorativo humano. Com a vontade de poder é feita a tentativa de

\footnotetext{
${ }^{6}$ Como é descrito de modo exemplar em JGB/BM, §188.

7 Um fragmento póstumo de 1881, apesar de breve, é bem elucidativo como um projeto para investigar esse processo (cf. XI, 26(391) p. 253 - verão - outono de 1884).
} 
compreender não só a origem dos movimentos e impulsos físicos e cosmológicos (da qual não nos ocuparemos nesse artigo), mas principalmente a dinâmica dos impulsos humanos em sua configuração (transmutação) na ética ${ }^{8}$.

O homem, ligado à comunidade, ao 'povo', é essencialmente avaliador. Ele confere sentido e valor às coisas, a si mesmo e a suas vivências. Nesse sentido, Zaratustra afirma não ter encontrado “... nenhum poder maior na Terra, do que o bem e o mal” (Za/ZA I, De mil e um fitos). As tábuas de bem e mal de cada povo expressam sua vontade de poder. Isso se aplica bem ao período da eticidade do costume, em que vigora o prazer pelo rebanho. O poder de criar valores, de louvar e censurar, cristalizou-se em costumes. Essas tábuas de valores, que os povos elevaram acima de si mesmos como uma autoridade superior, constrangem os indivíduos a associarem-se, de modo a somente encontrarem prazer em meio à comunidade. Esse prazer será sentido e denominado como virtuoso.

A vida, impulso incessante de superar a si mesma, atua em todos os seres vivos, de modo mais potente nos humanos, nas relações de mando e de obediência:

Onde encontrei vida, encontrei vontade de poder; e ainda na vontade do servo encontrei a vontade de ser senhor.

Que o mais fraco sirva o mais forte, a isto o induz a sua vontade, que quer dominar outros mais fracos: esse prazer é o único de que ela não quer prescindir. (Za/ZA II, Do superar si mesmo)

São os indivíduos que se sobressaem pela qualidade e quantidade superior de sua vontade de poder os que criam valores. Posteriormente, esses valores são hipostasiados como tendo uma origem "divina", supraindividual. O que importa aqui, no entanto, é que os nobres criadores exercem "um poder mais forte" ao estabelecer valores de bem e mal. Ingressamos, com isso, no domínio da formação das 'virtudes' tipicamente humanas, que são "batizadas" com nomes, com os valores de 'bem' e de

\footnotetext{
${ }^{8}$ Acerca da função decisiva da vontade de poder no processo de criação de valores e de domínio de si nos indivíduos que buscam autonomia na ética, cf. XI, 35(60), p. 538 e XII, 10(138), p. 535.
} 
'mal', a expressão mais nítida da vontade de poder da vida que superar a si mesma. É a vontade de poder que determina toda avaliação humana, inclusive a transmutação dos impulsos e paixões da natureza original em virtudes.

Nietzsche somente afirma, na primeira parte de Assim falou Zaratustra, que as paixões humanas transformam-se em virtudes:

Um tempo, tiveste paixões e as dizias más. Agora, porém, restam-te somente as tuas virtudes: brotaram das tuas paixões.

No centro das tuas paixões puseste o teu alvo mais alto: tornaram-se elas, então, as tuas virtudes e alegrias. (...) Todas as tuas paixões, por fim, tornaram-se virtudes e todos os teus demônios, anjos. (Za/ZA I, Das alegrias e das paixões).

Implicitamente, ele pressupõe nessa afirmação, que o homem pode tomar distância de suas paixões, enquanto as avalia como 'boas' ou 'más'. Se não há uma diferença qualitativa entre paixões boas e más, o resultado de atribuir um juízo negativo de valor às paixões têm um resultado bem definido: a despotenciação da paixão em virtude. Quando as paixões são afirmadas como boas, teríamos com isso novas e distintas virtudes? Não é descrito minuciosamente, no entanto, como ocorre esse processo de transformação das paixões (Leidenschaften) em virtudes. Até mesmo o "alvo mais alto" posto no núcleo mais íntimo das paixões, não seria ele mesmo uma paixão? Nessa seção, o autor de Zaratustra está mais preocupado em encetar o caminho para o além-do-homem, através da posse de uma única virtude, do que propriamente expor a gênese da virtude.

Uma tentativa mais consistente para mostrar a gênese da virtude ocorre quando Nietzsche/Zaratustra mostra o processo de transformação dos impulsos do corpo em espírito. Virtudes seriam "símbolos das elevações" do corpo, ou seja, uma sublimação de tendências instintuais ao longo da história humana. O espírito seria somente "arauto, companheiro e eco" das lutas e superações dos impulsos corporais. O que quer dizer nesse contexto "símbolo" (Gleichniss)? 
Símbolos, são todos os nomes do bem e do mal: nada exprimem, somente aludem. Tolo quem deles quiser tirar conhecimento.

Prestai atenção, meus irmãos, a cada hora em que o vosso espírito quer falar por símbolos: ali está a origem da vossa virtude.

É ali que o vosso corpo se acha elevado e ressuscitado; com seu deliciar-se, enleva o espírito, para que se torne criador e julgador de valores e amante e benfeitor de todas as coisas. (Za/ZA I, Da virtude dadivosa, §1)

Ao enaltecer o poder imenso da virtude, Nietzsche não quer despotencializar o movimento instintivo. Para isso ele iguala virtude e valor, ao afirmar: que a virtude "é um novo bem e um novo mal" (idem), em suma, o maior poder do ser humano que avalia. Inversamente, o poder (die Macht) é a nova virtude, o que determina todas as valorações humanas. Virtude seria, nessa perspectiva, toda propriedade, qualidade ou disposição sentida e estimada como prazerosa por seu possuidor. Ela é o próprio contentamento que surge nessa complexa organização fisiopsicológica, a saber, num corpo sadio que se supera numa espiritualidade superior.

O problema é que certos impulsos, próprio de nobrezas antigas, como a grega e a romana, são apenas 'apelidados' de "virtudes" (Tugenden). A compaixão, p. ex., não é vista ainda como uma virtude moral pelos romanos de velha cepa. Ela é extramoral (aussermoralisch), e só entrará para o reino das valorações morais quando o temor ao próximo, móvel efetivo da moral do rebanho, estabelecer essa virtude para o bemestar da comunidade. Na moral do animal de rebanho, a mediania, ou melhor, a mediocridade no desejar e no estimar, teria como resultado a igualdade, o afastamento dos perigos internos (passionais) e externos, em suma, o triunfo dos valores e virtudes típicos do "cordeiro", como a mentalidade modesta e submissa (cf. JGB/BM, §201).

A moral do rebanho, portanto, é o processo vitorioso na modernidade, no qual as paixões são degradadas em virtudes. Os impulsos perdem seu vigor natural (primeiro) através dos valores e virtudes, como a compaixão, a igualdade, a democracia, a simpatia por tudo o que sofre... A degeneração global do homem é tudo o que se pode esperar da 
despotenciação dos impulsos, típica das virtudes do rebanho. Esse supremo perigo, a ameaça de um novo budismo europeu (cf. JGB/BM, §202), para o defensor da nova nobreza, poderia gerar um movimento de superação das consequências niilistas da moral do rebanho. $\mathrm{O}$ ser humano enobrecido poderia ainda reunir e concentrar em si forças, cultivar certas virtudes, para assumir a nova tarefa, de determinar valorativamente o futuro do homem.

Como implantar no nobre novos instintos, novos hábitos, uma segunda natureza que esmaeça a natureza originária (primária) das pulsões, até tornar-se preponderante (primeira)? Essa questão se impõe como um desafio na investigação do pensamento ético nietzschiano, em confronto com a filosofia moral moderna e contemporânea.

Nesse ponto de "amolecimento e adoecimento doentio", a que chega a sociedade moderna, Nietzsche propõe um contramovimento, a saber, novas posições valorativas que brotem de seres com impulsos afirmativos e elevados do ponto de vista espiritual. A necessidade de uma nova nobreza (eines neuen Adels) já havia sido posta na terceira parte de Assim falou Zaratustra. Os 'novos nobres' é que deveriam tornar-se criadores - de novos costumes, de novos valores, de seu próprio caráter (?) - ao escrever em "novas tábuas a palavra 'nobre' (edel $)^{9}$. Em Além do bem e do mal, no entanto, a tarefa de engendrar uma nova nobreza deveria ser assumida por novos filósofos. São eles que, de posse de suas verdades, movidos por sua espiritualidade superior e autônoma, propõem valorações opostas às da moral do animal de rebanho. Os filósofos do futuro não seriam apenas arautos da nova nobreza, em contraposição às medíocres virtudes morais do tempo moderno; eles mesmos seriam nobres (vornehm).

A fixação de novas virtudes e de novos traços típicos de caráter, lamentavelmente, não é possível no curso de uma existência nobre. Seria preciso que muitas gerações cultivassem a grandeza no sentir, no pensar e no avaliar, imprescindível também aos espíritos livres e aos filósofos do futuro. Não é uma tarefa para qualquer um, pois nesse determinismo nietzschiano, conta a ascendência, o fato de ter nascido e ter sido educado para essa grandeza. Sem dúvida, eles teriam também de suportar o peso enorme da tarefa de transvalorar valores eternos. Zaratustra estava só no alto de sua montanha, com velhas tábuas quebradas e novas tábuas escritas

${ }^{9} \mathrm{Cf}$. Za/ZA III, De velhas e novas tábuas, $\S \S 11$ e 12. 
pela metade. Os filósofos do futuro são ainda solitários, mas já têm a consciência da grande responsabilidade para exercer a justiça e a arte do comando:

Muitas gerações devem ter trabalhado na gênese do filósofo; cada uma de suas virtudes deve ter sido adquirida, cultivada, transmitida, incorporada, e não apenas o passo e curso ousado, leve e delicado de seus pensamentos, mas sobretudo a disposição para grandes responsabilidades, (...) o prazer e o exercício da grande justiça, a arte do comando, a amplidão da vontade, a lentidão do olhar que raramente admira, raramente olha para cima, raramente ama...

Mas o que é nobre, no fim dessas considerações sobre a nobreza dos filósofos do futuro? Parece-nos que o nobre é ainda pobre de virtudes e de traços típicos afirmativos de caráter. Em Além do bem e do mal Nietzsche dá início à construção de novas virtudes, à medida que aborda as condições prévias para a sua nova tarefa. As virtudes devem harmonizar-se com os "mais íntimos e autênticos pendores" do indivíduo autônomo (cf. JGB/BM, $\S 214)$. A espiritualidade superior, propriedade indispensável dos filósofos do futuro e da nova nobreza, só poderia surgir como rebento de "qualidades morais" (JGB/BM, §219). Esse é um dilema no pensamento ético nietzschiano, à medida que ele procura assegurar a intensidade das paixões nas virtudes do nobre, recorrendo ao mesmo tempo a elementos degradantes da moral. O movimento da moral teria resultados bem distintos: nos valores e virtudes decadenciais do animal de rebanho e na espiritualidade superior (carente ainda de paixões veementes) própria da nova nobreza.

Em contraposição às virtudes dos homens do sentido histórico (bravura, desinteresse, honestidade, modéstia...), o homem de uma cultura nobre ${ }^{10}$ tem sobretudo as qualidade do bom gosto, da autossuficiência com o que possui, com a felicidade e com as transfigurações atingidas (cf.

\footnotetext{
10 É na "França do gosto", matriz da "cultura mais espiritual e mais refinada da Europa" que Nietzsche estima encontrar as mais nobres transfigurações da noblesse européia. À diferença do plebeísmo das ideias modernas inglesas e à 'enfermidade alemã do gosto', a superioridade da cultura francesa na Europa se manifesta através das paixões artísticas (culto à forma), da cultura moralista complexa (nas investigações e descobertas psicológicas) e a síntese semilograda do Norte e do Sul. Stendhal e Bizet são expressões geniais dessa cultura nobre (cf. JGB/BM, §254).
} 
JGB/BM, §214). A nobreza futura, no entanto, não tem a superabundância e a autossuficiência que o filósofo solitário encontra nos gênios já mortos da senil cultura francesa. Esses novos nobres ainda estão por vir. Seus bravos arautos, os espíritos livres, ainda possuem as virtudes do sentido histórico. É preciso avançar, e estabelecer as 'quatro virtudes cardeais', indispensáveis para se chegar a um novo tipo de nobre: coragem, perspicácia, simpatia e solidão (JGB/BM, §284). Esse isolamento é imprescindível para o autodomínio e para controlar os afetos desordenados do homem moderno. Ao buscar em si a virtude, ao reverenciar em si mesmo as mais excelsas transfigurações de sua existência, o nobre incorre numa inusitada forma de despotenciação dos impulsos. Nas obras e nos traços típicos de caráter do nobre deveria expressar-se uma espiritualização superior dos impulsos, em harmonia com a vontade de poder "intacta" do homo natura. No processo de moralização "toda virtude tende à estupidez". O espírito livre que prepara o nobre deve ser honesto o bastante para não recair nas seduções da moral. Sua vontade de poder "mais espiritual" almeja os reinos da futura nobreza. Como superar o mundo esvaziado de valores e de virtudes em que os solitários espíritos livres vivem? Não encontramos ainda na excelência ética da nova nobreza a potenciação dos impulsos naturais. Solitário e confinado no egoísmo próprio de sua 'alma', o novo nobre nietzschiano tem o desafio enorme de combater a decadência moral de sua época e poucas condições para fruir de sua autossuficiência. 


\section{Referências:}

AZEREDO, V. D. de. "A eticidade do costume. A inscrição do social no homem", in: Revista Dissertatio, $\mathrm{n}^{\circ} .25$. Pelotas: Departamento de Filosofia, Inverno de 2007, p. 73-90.

GERHARDT, V. "Selbstbegründung. Nietzsches Moral der Individualität", in: Nietzsche-Studien 21. Berlim: de Gruyter, 1992, p. 28-49.

GIACÓIA Jr., O. Nietzsche \& Para além de bem e mal. Rio de Janeiro: Jorge Zahar, 2002.

HÖFE, O. (org.). Zur Genealogie der Moral. Berlim: Akademie Verlag, 2004.

HUME, D. A Treatise of Human Nature. Ed. por L. A. Selby-Bigge e P.H. Nidditch. Oxford: Clarendon Press, 1975.

. Tratado da natureza humana. 2a . ed. São Paulo: Ed. UNESP, 2009.

MacINTYRE, A. Depois da virtude. Trad. de Jussara Simões. Bauru/SP: EDUSC, 2001.

MARTON, S. Nietzsche: Das forças cósmicas aos valores humanos. São Paulo: Brasiliense, 1990.

NIETZSCHE, F. W. A genealogia da moral. Trad. de Paulo C. de Souza. São Paulo: Companhia das Letras, 1998.

Aurora. Trad. de Paulo C. de Souza. São Paulo: Companhia das Letras, 2004. Livro, 1990.

Assim falou Zaratustra. Trad. de Mário da Silva. São Paulo: Círculo do Além do Bem e do Mal. Prelúdio a uma Filosofia do Futuro. Trad. de Paulo C. de Souza. São Paulo: Companhia das Letras, 1992.

. Humano, demasiado humano. Trad. de Paulo C. de Souza. São Paulo: Companhia das Letras, 2000.

. Sämtliche Werke. Kritische Studienausgabe (KSA). 15 vols. Organizada por Giorgio Colli e Mazzino Montinari. Berlim: de Gruyter, 1988.

RÉE, Paul. Der Ursprung der moralischen Empfindungen (1877). In: Gesammelte Werke (1875-1885). Org. Por Hubert Treiber. Berlim: de Gruyter, 2004.

RAWLS, John. Geschichte der Moralphilosophie. Hume - Leibniz - Kant - Hegel. Trad. de Joachim Schulte. Frankfurt: Suhrkamp, 2004. 
SCHOPENHAUER, A. Die beiden Grundprobleme der Ethik. In: Werke in fünf Bänden, vol. III. Zurique: Haffmans Verlag, 1999.

. Sobre o fundamento da moral. São Paulo: Martins Fontes, 2001.

Email: clademir.araldi@gmail.com

Recebido: Abril/2011

Aprovado: Maio/2011 